Discussion Papers No. 232, September 1998

Statistics Norway, Research Department

Runa Nesbakken

\title{
Price Sensitivity of Residential Energy Consumption in Norway
}

\begin{abstract}
:
The main aim of this paper is to test the stability of the results of a model which focus on the relationship between the choice of heating equipment and the residential energy consumption. The results for the income and energy price variables are of special interest. Stability in the time dimension is tested by applying the model on micro data for each of the years 1993, 1994 and 1995. The parameter estimates are stable within a 95 per cent confidence interval. However, the estimated impact of the energy price variable on energy consumption is considerably weaker in 1994 than in 1993 and 1995. The results for two different income groups in the pooled data set are also subject to stability testing. The energy price sensitivity in residential energy consumption is found to be higher for high-income households than for low-income households.
\end{abstract}

Keywords: Household energy consumption, space heating system, discrete-continuous choice, parameter stability.

JEL classification: C52, D12, Q41.

Acknowledgement: I would like to thank John K. Dagsvik, Bente Halvorsen, Bodil Larsen and Steinar Strøm for helpful comments.

Address: Runa Nesbakken, Statistics Norway, Research Department, P.O.Box 8131 Dep., N-0033 Oslo. E-mail: rne@ssb.no 

Discussion Paper can be longer and more elaborated than a usual article by including intermediate calculation and background material etc.

Abstracts with downloadable postscript files of

Discussion Papers are available on the Internet: http://www.ssb.no

For printed Discussion Papers contact:

Statistics Norway

Sales- and subscription service

P.O. Box 8131 Dep

$\mathrm{N}-0033$ Oslo

Telephone: +4762885500

Telefax: $\quad+4762885595$

E-mail: Salg-abonnement@ssb.no 


\section{Introduction}

Residential energy consumption in Norway has increased steadily during the last years. This development is due to economic growth and household behavior demanding more services from energy consumption. These services include heated air, heated water, lighting and services from electrical appliances. The increase in energy consumption is worrying because of increased $\mathrm{CO}_{2}$ emissions and other environmental problems. To meet the targets established by the Kyoto protocol it might be necessary to introduce increased taxes on fossil fuel use.

More than 70 per cent of the Norwegian residential energy consumption is electricity use. Until recently the electricity demand was covered by electricity from hydropower, with no $\mathrm{CO}_{2}$ emissions involved. However, during the last years electricity has been imported from the Nordic countries, especially from Denmark, to cover the increase in demand. Danish electricity production is mainly based on coal, which results in $\mathrm{CO}_{2}$ emissions. The Norwegian government is considering to introduce taxes on electricity consumption to moderate the increase in energy consumption.

Due to the ongoing political debate concerning introduction of new energy taxes, politicians, the electric utilities and others working on energy issues are interested in whether energy prices have an effect on energy consumption, and if so, whether this effect is strong. As can be seen from table 1, the estimates of income and energy price elasticities found in the literature show large variation. The results vary for several reasons. First, some models are applied on aggregated time series data, while others are applied on cross-sectional micro data. Second, the variation may be due to different types of models. Third, even though the models are similar, the observable and unobservable characteristics of the households may vary across countries. Vaage (1998) compares different methods of estimating electricity consumption and also finds large variation in income and price elasticities. He suggests that more time should be spent on testing existing models on new data.

In the last decade there has been a trend towards using disaggregated data to model household energy consumption. Improved computer capacity has made this possible. There is a lot of individual variation in household energy consumption, and accordingly the estimates of the price elasticity are more reliable when micro data are used. The considerable variation in estimates of energy price elasticities makes it difficult to find the best estimate of this elasticity. Even though some of the results are based on models applied on cross-sectional data, more information about energy price sensitivity is needed to find a good estimate of the impact on energy consumption of introducing or increasing energy taxes. This paper intends to shed light on this topic. 
Table 1. Estimates of income elasticities and price elasticities for electricity consumption in the literature. Estimated on micro data

\begin{tabular}{lcc}
\hline Reference & $\begin{array}{c}\text { Income } \\
\text { elasticity }\end{array}$ & $\begin{array}{c}\text { Electricity } \\
\text { price } \\
\text { elasticity }\end{array}$ \\
\hline $\begin{array}{l}\text { Aasness, J. and B. Holtsmark (1993). Norway. Household data. Long run } \\
\text { results. }\end{array}$ & 0.28 & -0.20 \\
\hline $\begin{array}{l}\text { Halvorsen, B. and B. Larsen (1998). Norway. Household data. Dynamic } \\
\text { model. Short run result. Long run price elasticity: -0.42 }\end{array}$ & -0.33 \\
\hline Parti, M. and C. Parti (1980). USA. Household data. Short run results & 0.15 & -0.58 \\
\hline $\begin{array}{l}\text { Morss, M.F. and J.L. Small (1989). USA. Short run-result. Long-Run: Income } \\
\text { elasticity 0.18, Price elasticity -0.38 and -0.43 for moderate customer growth } \\
\text { and high customer growth respectively. }\end{array}$ & 0.08 & -0.23 \\
\hline $\begin{array}{l}\text { Baker, P., } \text { R. Blundell and J. Micklewright (1989). United Kingdom. } \\
\text { Elasticities for sub-groups of households are presented in this paper. }\end{array}$ & 0.17 & -0.76 \\
\hline $\begin{array}{l}\text { Dennerlein, } \text { R.K.H. (1987). Germany. Total demand elasticities for mean } \\
\text { income. Household data. Discrete-continuous choice model (Electrical } \\
\text { appliances). Total elasticities. }\end{array}$ & 0.42 & -0.38 \\
\hline $\begin{array}{l}\text { Dubin, J.A. and D.L. McFadden (1984). USA. Point estimates for average } \\
\text { demand (electricity and gas). Discrete-continuous choice model (Heating } \\
\text { equipment). }\end{array}$ & 0.02 & -0.26 \\
\hline $\begin{array}{l}\text { Bernard, J.T., D. Bolduc and D. Bélanger (1996). Canada. Discrete-continuous } \\
\text { choice model (Heating equipment). Short run results from IV-method. }\end{array}$ & 0.14 & -0.67 \\
\hline $\begin{array}{l}\text { Branch, E.R. (1993). USA. Expenditure Survey Data. Short run results. } \\
\text { Garbacz, C. (1983). USA. Total elasticities. Partial elasticities are 0.102 for } \\
\text { income and -0.193 for price. }\end{array}$ & 0.23 & -0.20 \\
\hline
\end{tabular}

A model which focuses on the relationship between the choice of heating technology and energy consumption in each household is used to estimate residential energy consumption. This model is applied on cross-sectional data from the Norwegian consumer expenditure surveys for the three years 1993, 1994 and 1995, which gives a unique opportunity to compare results over time. Previously, the model of this paper is applied on data from the 1990 energy survey (Nesbakken, 1998). Because the estimation results are based on cross-sectional data for one specific year including a particular sample of households, the main results are compared to the results of this paper. Furthermore, the pooled data set for 1993-95 is divided into two subsets, depending on household income, to test for stability across households. The stability of income and energy price elasticities, both over time and across households, are of special interest. 
The model is presented in section 2 of the paper. In section 3 the data are described. This is followed by results for the years 1993, 1994 and 1995 in section 4. Furthermore, results for pooled data are presented for all households and for two different income groups. Income and energy price elasticities are estimated. Finally, some concluding remarks are made.

\section{Model and estimation method}

The main aim of the model used in this paper is to take into consideration the relationship between the choice of heating system (the discrete choice) and utilization of the heating system (the continuous choice). Here, the presentation of the formal part of the model is restricted to show the indirect utility function and the equations to be estimated. For more information about the model, see Nesbakken (1998). Other works which focus on the link between energy-using equipment and energy use are, for instance, Dubin and McFadden (1984), Hausman (1979), Dennerlein (1987) and Bernard et al. (1996).

The model is formulated to take into account different features of the heating equipment and energy consumption. Our main aim is to analyze the household's total residential energy consumption. We do not model consumption of each fuel type. Second, more than two thirds of Norwegian households have more than one type of heating equipment, and the discrete choices consist of mixed heating systems. The model takes into consideration the fact that the discrete and continuous choices are related to different points in time. The choice of heating technology is related to new houses. In this paper, only houses built after 1970 are considered, because cost data of the heating equipment for the previous years are inadequate. The data give information about energy consumption in 1993, 1994 and 1995. We assume that the heating technology observed in 1993, 1994 or 1995 is the same as the technology purchased when the house was built. Finally, the model captures the possibility of correlation between unobservable variables in the discrete and the continuous stages.

The household chooses among the following four mutually exclusive heating technologies, which are grouped by fuel use:

- Electricity (electric heaters)

- Electricity and oil (electric heaters combined with stoves for oil/kerosene)

- Electricity and wood (electric heaters combined with wood stoves)

- Electricity, oil and wood (electric heaters combined with stoves for oil/kerosene and stoves for wood) 
All types of equipment were not necessarily used at the point when we study the utilization. A household that has chosen a technology which uses electricity, oil and wood might have used, for instance, only electricity in 1995. Households using electric heaters combined with wood stoves or stoves for oil/kerosene often use electricity as base heating equipment. In the coldest periods of the winter the other equipment is used in addition to cover the peak power demand. Electric heaters as the only available heating equipment is most common in apartment buildings with relatively small dwelling size. Accordingly, households which have only electric heaters use far less energy than households using other heating systems.

\subsection{Econometric model}

The utility of the household depends on energy consumption, consumption of other goods, observable characteristics of the household and the dwelling, unobservable characteristics of the household and unobservable characteristics of the heating equipment. The household is assumed to choose the heating system $j$ which gives the highest utility. The utility derived from maximizing the utility function can be represented by the indirect utility, $V_{j}$. The specification of this indirect utility function, which is related to the choice of heating system $j(j=1, \ldots, \mathrm{J})$, is given by

$$
V_{j}=\left[Z_{1}^{\prime} \alpha_{0 j}+\sum_{h=1}^{H} \frac{\alpha_{h}}{\beta}+\sum_{h=1}^{H} \alpha_{h} P_{h}+Z_{2}^{\prime} a+\beta\left(Y-B_{j}\right)+\gamma_{j} Y^{*}+\widetilde{\eta}\right] \exp \left(-\beta P_{1}\right)+\varepsilon_{j}
$$

where $Z_{1}^{\prime}$ and $Z_{2}^{\prime}$ are the dwelling and household characteristics related to the discrete and continuous choices, respectively. Variables included in the vector $Z_{1}^{\prime}$ are, for instance, dwelling ownership and type of house, while examples of variables included in $Z_{2}^{\prime}$ are dwelling size, degree days and number of children. Furthermore, $Y$ denotes household income, $P_{h}$ is the price of energy type $h(h=1, \ldots, \mathrm{H})$, where $P_{1}$ is the electricity price, and $B_{j}$ is the total costs of choosing heating system $j$. The total costs consist of the annualized capital costs and operating costs of the heating system. $Y^{*}$ is income at the point in time when the heating system is purchased. We assume that $Y^{*}$ is a proxy for unobserved factors correlated with income which may influence the household's preferences for different heating systems. $\gamma_{j} Y^{*}$ represents the possible indirect impact of income on the heating system choice. $\eta$ and $\varepsilon_{j}$ denote unobserved characteristics related to the household's preferences for indoor temperature and heating systems, respectively. We allow $\varepsilon_{j}$ and $\eta$ to be stochastically dependent. $\widetilde{\eta}$ is an 
expected value of the variable $\eta$ which captures both factors which are known to the household and uncertain factors related to energy demand. $\varepsilon_{j}$ is assumed to be identically and independently extreme value distributed for all choices $j$, given the household. $\alpha_{0_{j}}, \alpha_{h}, \gamma_{j}$ and $\beta$ are parameters to be estimated. When the household is assumed to choose the heating technology which gives the highest utility and $\varepsilon_{j}$ is assumed being extreme value distributed, this yields the following probability of choosing heating technology $j$ (see McFadden, 1973)

$$
\pi_{j}=\frac{\exp \left[\left(Z_{1}^{\prime} \alpha_{0 j}-\beta B_{j}+\gamma_{j} Y^{*}\right) \exp \left(-\beta P_{1}\right)\right]}{\sum_{k=1}^{K} \exp \left[\left(Z_{1}^{\prime} \alpha_{0 k}-\beta B_{k}+\gamma_{k} Y^{*}\right) \exp \left(-\beta P_{1}\right)\right]}
$$

That is, the heating system choice is given by a generalized version of the multinomial logit model. Using Roy's identity on (1) gives the energy consumption of each energy type, $X_{h j}$. By summing up we find that the household's total energy consumption conditional on the choice of heating system is given by

$$
X_{j}=Z_{1}^{\prime} \alpha_{0 j}+\gamma_{j} Y^{*}+\beta\left(Y-B_{j}\right)+\sum_{h=1}^{H} \alpha_{h} P_{h}+Z_{2}^{\prime} a+\eta
$$

Because we now look at intensity of use, the variable $\eta$ is no longer uncertain. When accounting for the possible selection bias associated with the fact that $E[\eta \mid j] \neq 0$, it can be shown that the household energy demand conditional on the choice of heating system $j$ is given by

$$
X_{j}=Z_{1}^{\prime} \alpha_{0 j}+\gamma_{j} Y^{*}+\beta\left(Y-B_{j}\right)+\sum_{h=1}^{H} \alpha_{h} P_{h}+Z_{2}^{\prime} a-\sigma_{j} \log \pi_{j}+\sum_{k \neq j} \sigma_{k} m_{k}+\mu_{j}
$$

where $\mu_{j}$ is a random variable with zero conditional expectation given that heating system $j$ is chosen, $\sigma_{k}=\sigma \rho_{k}, m_{k}=\frac{\pi_{k} \log \pi_{k}}{l-\pi_{k}}$, and $\rho_{j}$ is the correlation between $\eta$ and $\varepsilon_{j}$. The selection term, $-\sigma_{j} \log \pi_{j}+\sum_{k \neq j} \sigma_{k} m_{k}$, captures the effect of the correlation between unobservable characteristics concerning the heating choice and unobservable characteristics concerning the utilization of the chosen heating technology. $\sigma_{j}$ is a parameter to be estimated. The selection term is derived in Dubin and McFadden (1984). The following example may help understanding the fact that correlation 
between unobservable characteristics is possible. A household which prefers a very high indoor temperature may, for instance, choose wood stoves to cover its high power demand. This choice of heating technology and the high energy consumption following from the preferences for indoor temperature may differ from what can be explained by the observable variables.

A common parameter $\beta$ is related to both income at the point of utilization of the heating system, and the costs related to the heating system. The interpretation of this is that an increase in income and a decrease in costs have the same impact on income disposable for other goods than energy.

Equations (2) and (4) are used to estimate the unknown coefficients of the model. However, the average energy price for energy types which may be used in the chosen heating system, and not each energy price separately, is used when estimating the model. This is due to the fact that total energy consumption is focused.

\subsection{Estimation method}

The discrete-continuous choice model is estimated simultaneously by using a full information maximum likelihood procedure, to ensure consistent estimates of $\beta$ over the discrete and the continuous stages of the model. Let

$$
Y_{i j}=\left\{\begin{array}{l}
1 \text { if household } i \text { chooses heating system } j, i=1, \ldots, N \text { and } j=1, \ldots, J \\
0 \text { else }
\end{array}\right.
$$


Then the log likelihood of the simultaneous model is given by

$$
L(\theta)=\sum_{i=1}^{N} \sum_{j=1}^{J}\left[Y_{i j} \log \left(\pi_{i j}(\theta) f_{i j}\left(X_{i j}\right)\right)\right]=\sum_{i=1}^{N} \sum_{j=1}^{J}\left[Y_{i j} \log \pi_{i j}(\theta)+Y_{i j} \log f_{i j}\left(X_{i j}\right)\right]
$$

where $\pi_{i j}(\theta)$ is the probability given in equation (2). Furthermore, $f_{i j}\left(X_{i j}\right)$ is a conditional probability density function following from equation (4), when the error term, $\mu_{j}$, is assumed to follow from a normal distribution with expectation zero and constant variance, given the heating system $j$.

\section{Data}

The model is estimated on cross-sectional data for the years 1993, 1994 and 1995 (see Statistics Norway, 1998), which contain information about the households' energy consumption and characteristics of the households. For wood, kerosene and oil we do not have information about the actual use, only procurement during the last 12 months, which in average may be a plausible proxy for actual use. Information about the heating technology of the households is also available. Cost data for different types of heating equipment are based on data from Institute for Energy Technology (IFE, 1995). Temperature data are provided from the Norwegian Institute of Meteorology. The variation in temperature during the year is measured in degree days, that is, the difference between $17 \mathrm{C}^{\mathrm{o}}$ and the outdoor temperature, summed up for each year. Thus, cold weather will result in high degree-day values.

Energy prices at the point when the heating equipment was purchased are used to explain the choice of heating system, covering the period from 1971 to 1995 . Electricity prices at municipal level for 198895 are collected from the Norwegian Water Resources and Energy Administration. For the period from 1971 to 1987 average electricity prices by county from the electricity statistics are used. Prices of oil and kerosene for this period are provided from the Norwegian Petroleum Institute and from the consumer price index at municipal level for the years 1988-95.

The wood prices for the period 1993-95 are calculated as average prices for each county based on information about the cost and quantity of wood in the consumer expenditure survey. It may be argued that the average price of wood should include the zero prices of wood by those who get the wood for free. In this paper, however, we use average wood prices based on those who actually pay for it. 
Again, this may be a plausible proxy taking into account the alternative value of time used by harvesting wood. For the period 1971-92 the wood prices are based on a price index for birch wood and an assessment of the level of the wood price in 1993.

The values of all variables used to estimate the heating choice are dated at the point when the heating equipment was chosen (in the period from 1971 to 1995), while the values of the variables used to estimate the continuous choice are dated at the point when the utilization took place, i.e. in 1993, 1994 or 1995. The values of all income and price variables are in constant 1993-prices.

Households which have central heating systems are excluded due to unsatisfactory data quality. Farm houses are not included because these households use a lot of wood (often for free) and often get hold of wood for several years, i.e. the stock of wood is not a good proxy for actual usage. Besides, information about the electricity use provided by the electric utilities includes electricity consumption related to running the farm.

\section{Results}

First, the model is estimated separately on data for the three years 1993, 1994 and 1995 to compare the estimation results along the time dimension. The parameter stability of a variable is tested by comparing the 95 per cent confidence intervals of the parameters. If the confidence intervals overlap, it is interpreted as stable parameters. Second, the main results from applying the model on data for 1990 are compared to the results for 1993-95. Because energy consumption for space heating is estimated for 1990, while the data for 1993, 1994 and 1995 only give estimation results for total residential energy consumption, the elasticitities, and not the parameter estimates, are compared.

The results of estimating on the pooled data for 1993-95 follows in the next section. The pooled data give more precise estimates than the results for each separate year because of more observations. To test whether income, energy prices and other variables have the same impact on energy consumption when the income level varies, the model is estimated for two income groups.

\subsection{A comparison of estimation results for 1993,1994 and 1995}

Estimation results for the years 1993-95 are presented in table 2. The estimates of the parameter for both income and heating system costs $(\beta)$ are reported first, where $\beta$ is a link between the discrete and the continuous parts of the model. Then the estimation results for ownership, house type, household size and income, which are related to the discrete part of the model, are reported. Estimates for the 
continuous part follow in the last part of the table. The results support standard economic theory expecting energy consumption to increase with income and to be negatively correlated with the energy price. The estimates of $\beta$, which differ significantly from zero, are 0.09 for 1993 and 1994, and about 20 per cent higher for 1995 . By comparing the confidence intervals, the $\beta$-parameter is found to be stable. The parameter estimates for the energy price variable are at the same level in 1993 and 1995, while the estimate for 1994 indicate less price sensitivity for this year. However, the parameters are not significantly different.

When estimating the discrete part of the model, electric heaters only is the reference alternative for the choice of heating system. For all discrete choice variables the parameters related to the reference choice are set equal to zero due to normalization. The partial impact of a variable on the preferences for a given heating system relative to the reference choice is found by comparing the parameter estimates ( $\alpha_{0 j}$ or $\lambda_{j}$ in equation 1 and 2 ). The household chooses the heating system which maximizes the utility. We find that the utility of choosing a heating system which uses only electricity is higher than the utility of choosing other heating systems when the household lives in housing co-operatives or owner-tenant accommodations, ceteris paribus. This result is found for all years (1993, 1994 and 1995). Furthermore, households living in detached houses are most likely (partial effect) to choose a heating system based on electricity and wood in 1993 and 1994. In 1995 the heating technology based on electricity, oil and wood is mostly preferred. In 1993 and 1994 the impact on utility of household size is highest for the heating system which uses electricity and wood. For the year 1995 the parameter for this heating technology is the only one that is significantly different from zero.

The results for the variables representing dwelling ownership, type of house and size of household show that even though the most preferred heating technology to a great extent is the same for the years 1993, 1994 and 1995, the ranking of the other alternative heating systems vary from year to year. The confidence intervals show that the parameters of the discrete choice variables for 1993, 1994 and 1995 are stable over time.

The results for household income, $Y^{*}$, show that a proxy for unobserved factors correlated with income does not influence the choice of heating system significantly. The only significant result at a 5 per cent level indicates that in 1995 the utility of choosing a heating system which uses electricity only is higher than the utility of choosing a heating technology based on electricity and oil. 
When considering the results from the continuous part of the model, we find that the estimates of the dwelling size and degree days variables are stable in the period from 1993 to 1995 . The results have the right sign and differ significantly from zero. The result of degree days indicates that the energy consumption is higher in the colder regions of the country.

If the household owns washing/drying equipment, the energy consumption increases for all three years, even though the parameter estimates vary a great deal. The cooling equipment estimate is significant at a 10 per cent level for the years 1993 and 1994 and insignificant for 1995. The number of children in the household is included as an indicator for the use of hot water, but only the result for 1993 is significant. The impact of age of the oldest person in the household is estimated to be the same for 1993 and 1995, while the result for 1994 is insignificant.

The results for the selection term (see equation 4) for 1993 and 1994 support the hypothesis of correlation between unobserved characteristics related to heating system choice and energy consumption. The results for 1995 are not significant. The ranking of the parameters is, however, approximately the same for the three years, which indicates that when the probability of choosing technologies based on wood (combined with electricity or both electricity and oil) increases, the impact on energy consumption is higher than when the probability of choosing other technologies increases. 
Table 2. The choice of heating system and residential energy consumption in dwellings from 1971-90. The reference choice is electricity (parameter=0). 1993, 1994 and 1995.

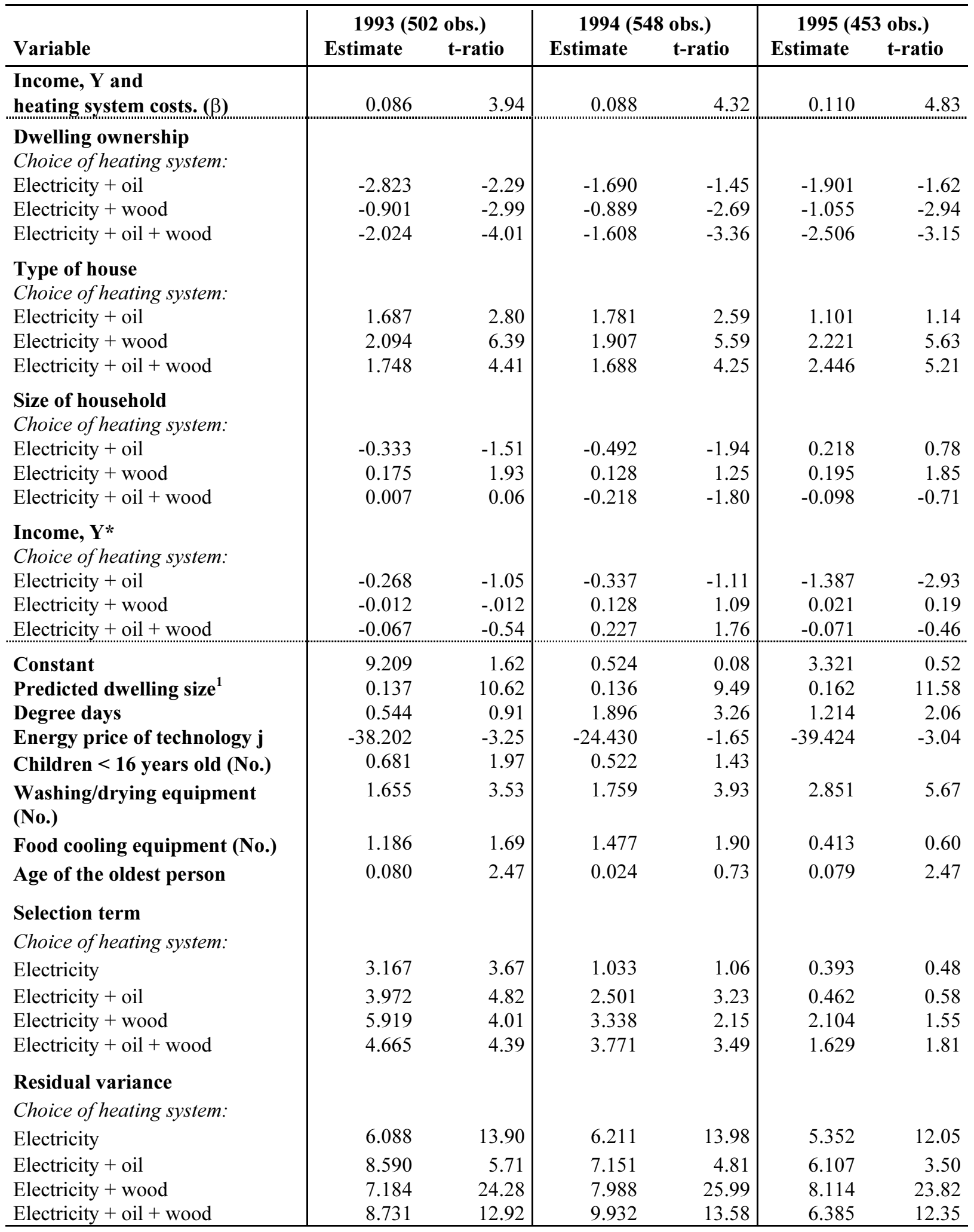

${ }^{1}$ Income at the point of time when the heating technology was purchased, the type of house and the size of household are used as instruments when estimating the dwelling size, see appendix C. 


\subsection{Income and energy price elasticities for $1993-95$}

Income and price elasticities on energy are based on the parameter estimates of the model, which are presented in table 2 , and the elasticities are estimated at sample means, see table A1 in appendix A. The short run income elasticities, which are based on estimates of the parameter $\beta$, are estimated to 0.01 for each of the years 1993, 1994 and 1995, see table 3. A linear relationship between the dwelling size, income, household size and type of house is estimated, see appendix C. The estimated dwelling size is used as instrument for the observed dwelling area in the continuous part of the model. In the long run, changes in income may change the dwelling size, and consequently the energy consumption. The long run income elasticity is calculated to 0.28 in 1993. It is reduced to 0.21 and 0.15 in 1994 and 1995. This is due to a reduction in the estimated impact of income on the dwelling size from 1993 to 1995. Observed dwelling size has increased from 1993 to 1995, despite of approximately unchanged average values of income, type of house and household size. One explanation of this may be the decline in real interest rates from 1993 to 1995.

The differences in the energy price elasticities from year to year are more striking than the differences in income elasticities. However, it should be noted that in this model energy demand is linear, and accordingly, the elasticities are not constant. Because mean values for energy consumption, income and prices only change to a little extent from one year to another, the elasticities are not expected to vary much. The impact of the energy price on the energy consumption in 1994 is very low (in absolute value) compared to the results for 1993 and 1995. The estimate for 1994 is significantly different from zero only at a 10 per cent level, while the results for 1993 and 1995 are significant at 0.2 per cent level. One possible explanation of the difference between the estimates of the energy price elasticity are distortions in the sample for 1994. Sample mean values of the variables included in the model are mainly at the same level for all three years. However, in 1994 income is higher, the household size is lower, the share of detached houses is smaller and the variation in age is higher than in 1993 and 1995.

Another reason why the energy price elasticity differs from year to year may be that variables which have effect on the households' sensitivity to energy price changes are excluded in the model. Campaigns for energy conservation or focus on energy prices in the news media may serve as examples of this type of excluded variables.

In Nesbakken (1998) the results of applying the model on data for 1990 are reported. The income and price elasticities for energy consumption in 1990 are included in table 3 to be compared to the results of this paper. The model which is applied is the same. However, there are some differences between 
the data from the 1990 energy survey and the data from the survey of consumer expenditure (SCE). The main differences are that energy for space heating and gross income are used in the estimation of the model for 1990, while total residential energy consumption and net income are used for the other three years. About 60 per cent of total residential energy consumption is related to space heating ${ }^{1}$.

The short run income elasticity for 1990 is estimated to be somewhat higher than for the other years, and the long run income elasticity is estimated to be on the average level of the 1993-95 results. The 1990-estimate of the energy price elasticity is low (in absolute terms) relative to the estimates for 1993 to 1995 . The explanation may be that only energy consumption for space heating is studied for 1990 , while total residential energy consumption is studied for 1993-95. There are substitution possibilities in energy consumption for space heating, but almost no substitution is possible in energy consumption for other purposes. Accordingly, the effect of energy price changes on energy consumption is less when energy for space heating is studied than when total energy is considered.

Table 3. Income and price elasticities for energy ${ }^{1} .1990^{2}, 1993,1994$ and 1995

\begin{tabular}{l|c|ccc}
\hline & $\mathbf{1 9 9 0}$ & $\mathbf{1 9 9 3}$ & $\mathbf{1 9 9 4}$ & $\mathbf{1 9 9 5}$ \\
\hline Short run income elasticity & 0.04 & 0.01 & 0.01 & 0.01 \\
Long run income elasticity & 0.21 & 0.28 & 0.21 & 0.15 \\
Short run energy price elasticity & -0.24 & -0.57 & -0.33 & -0.53 \\
\hline
\end{tabular}

${ }^{1}$ Estimated at sample means.

${ }^{2}$ The estimation results for 1990 are given in appendix B.

${ }^{3}$ Includes the impact of income on the dwelling size, which in turn has impact on energy consumption, see appendix C.

Henley and Peirson (1998) show that the energy price responsiveness of heating energy demand is dependent on temperature. The average temperature was lower in 1990 than in 1993-95. The degree day variable partly captures the effect of temperature differences in the model of this paper. The interaction of temperature and energy price sensitivity is, however, not considered.

\subsection{Estimation results for different income groups (pooled data)}

When estimating the model for 1993, 1994 and 1995 the sample for each year consists of heterogeneous households with respect to for instance income, type of house and age of the household

\footnotetext{
${ }^{1}$ Furthermore, the 1990 survey gives information about the use of wood, kerosene and oil, while the SCE for 1993, 1994 and 1995 only give information about the purchased quantity of these energy types. Households in farm houses are excluded from the SCE-data, while these households are included in the 1990-data. Finally, the variables included in the estimation for 1990 are not identical to the ones included for 1993-1995, even though the most important variables are the same.
} 
members. The households' preferences may differ in many respects. Poyer et al. (1997) study energy consumption for different population groups and find significant variation in the consumption patterns by Latino and non-Latino households. In Yamasaki and Tominaga (1997) it is focused on the relative high energy consumption of elderly households compared to other households in Japan. Accordingly, it is reason to believe that energy consumption may vary between household groups in many respects. If the energy price elasticity varies across household groups, introduction of an energy tax may affect these household groups differently. Quite often the effect on different income groups of introducing taxes are of special interest for the politicians

In the model of this paper it is assumed that the functional form of the utility is the same across households and that the marginal utility of income is constant. If all households have approximately the same preferences, the estimated parameters for different household groups should be nearly the same, too. To test the stability of the parameters across different income groups, the model is applied on two subsets for income higher and lower than the mean income. The marginal utility of income is given by $\beta \exp \left(-\beta \mathrm{p}_{1}\right)$, and the assumption of constant marginal utility with respect to income is evaluated by comparing the estimates of $\beta$ for the two income groups.

The model is applied on the pooled data set for 1993 to 1995 to give average estimates for the period 1993 to 1995, see the first column of table 4. Results for the two income groups are given in the next columns. The pooled data set is used to avoid estimation on very small data subsets. The parameter which represents the impact of income on energy consumption and the impact of costs on the heating system choice $(\beta)$, is estimated to be 0.09 when all households are included. The same estimate for $\beta$ was found for 1993 and 1994, se table 2. When estimated on the two data subsets, the parameter estimates are 0.12 and 0.07 for the low-income and high-income groups, respectively. Even though the estimates differ quite much, the 95 per cent confidence interval indicates that the estimates of $\beta$ are stable across income groups. 
Table 4. The choice of heating system and residential energy consumption in dwellings from 1971-1990. The reference choice is electricity (parameter=0). Pooled data 1993-95. 1503 observations

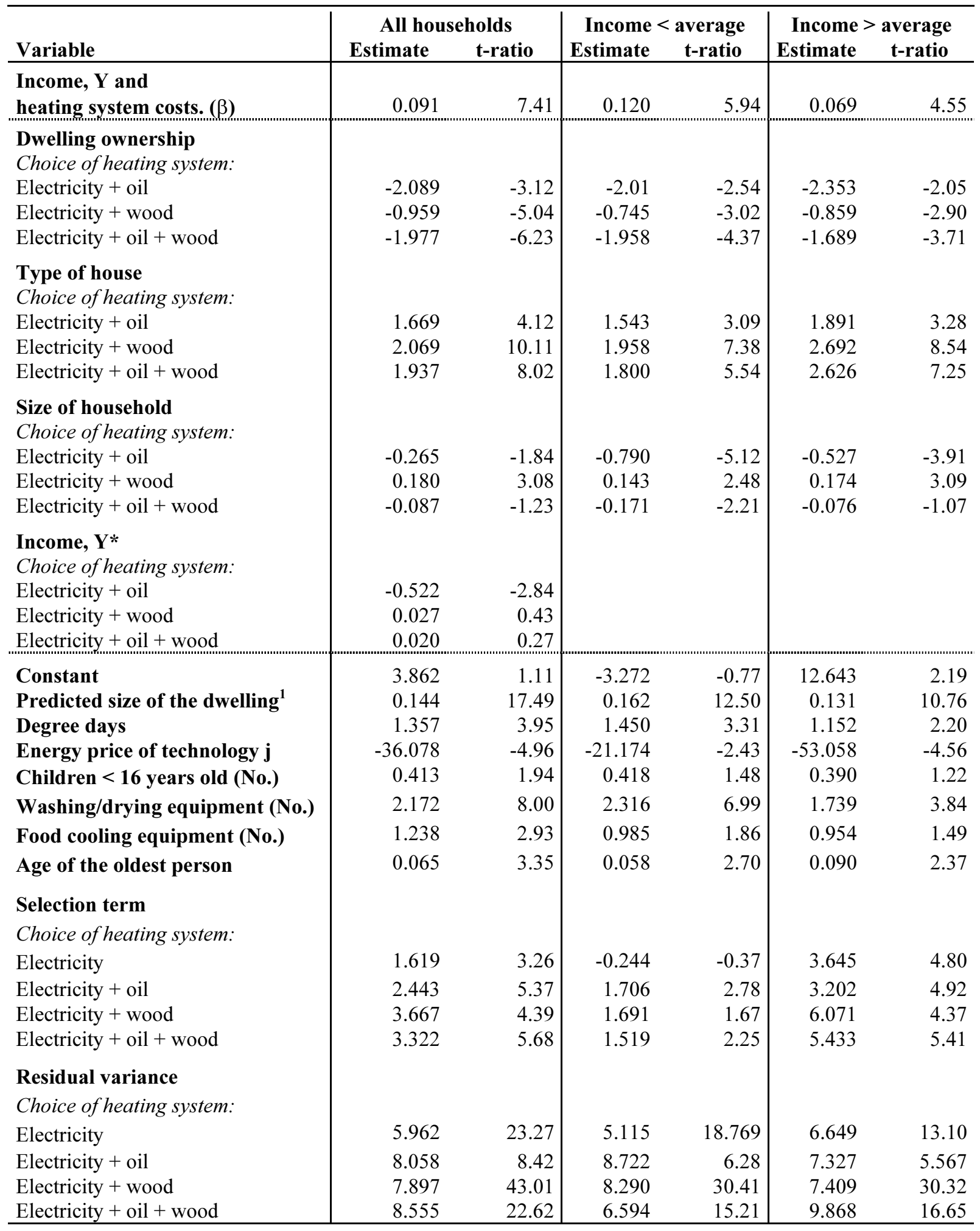

${ }^{1}$ Income at the point in time when the heating technology was purchased, the type of house and the size of household are used as instruments when estimating the dwelling size. 
Most of the parameter estimates for dwelling ownership, type of house and household size differ significantly from zero at 5 per cent level and show stability with respect to income groups. The results for the continuous choice variables also show stability. The parameter estimate of the energy price for high-income households is, however, more than twofold the estimate for low-income households (in absolute terms). Nevertheless, the confidence intervals overlap somewhat.

The results for the selection term vary considerably across income groups. For all heating technologies it is found that the impact on energy consumption is higher for high-income households than for lowincome households when the probability of choosing a given heating technology increases. This might be due to different levels of energy consumption and shares of households choosing the different heating technologies. However, when calculating elasticities for the technology based on electricity and wood, the impact on energy consumption for high-income households is still strongest.

Comparison of the 95 per cent confidence intervals of the parameters shows that the parameters for the heating system which uses electricity, oil and wood are different for the two income groups, while the parameters for the heating system based on electricity and oil and the system based on electricity and wood are stable. The differences in the effect of the selection term on energy consumption indicate that the impact of excluded variables is higher for the high-income group than for the low-income group. An interpretation of this is that the preferences of the households in the two income groups are different with respect to unobserved variables.

Most parameter estimates indicate a high degree of stability for the two income groups. The significant unstability of the selection term parameter across income groups indicates, however, that the hypothesis of equal utility function for all households should be subject to more testing.

\subsection{Income and price elasticities for different income groups}

The parameter estimates reported in the previous section indicate that the impact of income on energy consumption varies between income groups. When calculating elasticities based on the parameter estimates, however, we find that the income elasticity only to a little extent depend on income groups, see table 5. The short run estimates are equal, while the long run income elasticity is calculated to 0.18 for low-income households and 0.22 for high-income households.

The short run energy price elasticity for all households is estimated to -0.50 . The energy price elasticity of high-income households is twice as high (in absolute terms) as the elasticity for lowincome households. The budget share of energy for high-income households is relatively low, and 
consequently one would expect high-income households not to be as energy price sensitive as lowincome households. However, our results show the opposite result. One explanation may be that the level of energy consumption is high and the marginal utility of energy is low for high-income households. Then a reduction in energy consumption due to energy price increases only give a small reduction in utility. When the energy price increases, space heating may be restricted to rooms which are frequently used, and the swimming pool need not to be used. The energy consumption of lowincome households is on a low level, and then it is very uncomfortable to reduce energy consumption if the energy price increases.

Our results indicate that high-income households are more sensitive to energy price changes than households with lower income. Income and price responsiveness may also vary across other household groups. The model was applied on households with children below 16 years and 7 years at age respectively, to investigate the energy price elasticity of households which have children. The results indicate that the household group with the smallest children is less sensitive to energy price increases than the other household group, despite the fact that the mean income was only 3 per cent lower for the households with small children than for the other group. The estimated energy price elasticities are -0.46 and -0.30 for households with children in all ages below 16 years and households with small children, respectively. However, this result may be reasonable because the expenditures for kindergartens or other types of child care are high relative to expenditures for children who have started school. Low income net of fixed child care costs for households with small children, and decreasing marginal utility of energy, may explain the low sensitivity to energy price changes for this household group relative to households having children at all ages up to 16.

Table 5. Estimated income and energy price elasticities ${ }^{1}$ for different income groups. Pooled data 1993-95

\begin{tabular}{lccc}
\hline & All households & Income $<$ average & Income $>$ average \\
\hline Short run income elasticity & 0.01 & 0.01 & 0.01 \\
Long run income elasticity $^{2}$ & 0.20 & 0.18 & 0.22 \\
Short run energy price elasticity & -0.50 & -0.33 & -0.66 \\
\hline
\end{tabular}

${ }^{1}$ Estimated at sample means.

${ }^{2}$ Includes the impact of income on the dwelling size, which in turn has impact on energy consumption, see appendix C. 


\section{Summary and conclusions}

In this paper the residential energy consumption for 1993-95 is modeled to discuss the stability of the estimated parameters, both over time and across income groups. The parameters show stability from year to year. However, the energy price parameter for 1994 is about 37 per cent lower (in absolute value) than the parameters for the other two years. A comparison of the t-ratios indicates that the results for 1993 and 1995 are more precisely estimated than the result for 1994. The estimate of the energy price elasticity for the pooled data set is -0.50 , which is quite close to the estimates for 1993 and 1995.

To find out how different preferences affect estimated energy demand, the model is applied on two subsets, one for income higher and one for income lower than the mean income. By comparing the confidence intervals of the parameters most of them show stability across the two income groups. However, the results for the variable capturing the correlation between unobservable preferences for heating system and utilization (the selection term) is found to be unstable. This indicates that the model assumption of an identical utility function for all households should be tested further.

Baker et al. (1989) show that the top deciles of the income distribution have the lowest income elasticity, while the results of this paper indicate that the long run income elasticity is slightly higher for high-income households than for low-income household. Furthermore, the results indicate that high-income households are more sensitive to energy price changes than low-income households. 
Appendix A

\section{Mean values}

Table A1. Mean values , $1990^{1}, 1993-1995^{2}$

\begin{tabular}{|c|c|c|c|c|}
\hline & $\begin{array}{r}1990, \\
550 \text { obs. }\end{array}$ & $\begin{array}{r}1993, \\
502 \text { obs. }\end{array}$ & $\begin{array}{r}1994, \\
548 \text { obs. }\end{array}$ & $\begin{array}{r}1995, \\
453 \text { obs. }\end{array}$ \\
\hline \multicolumn{5}{|l|}{ Share with heating system based on: } \\
\hline Electricity & 0.19 & 0.20 & 0.18 & 0.17 \\
\hline Electricity and oil & 0.03 & 0.04 & 0.02 & 0.02 \\
\hline Electricity and wood & 0.60 & 0.59 & 0.62 & 0.64 \\
\hline Electricity, oil and wood & 0.18 & 0.17 & 0.17 & 0.17 \\
\hline Energy consumption ${ }^{3},\left(10^{-3} \mathrm{kWh}\right)$ & 13.03 & 25.56 & 26.78 & 27.70 \\
\hline \multicolumn{5}{|l|}{ Annual capital cost ${ }^{4}\left(10^{-2}\right)$ for heating system based on: } \\
\hline Electricity & 9.77 & 9.49 & 9.47 & 9.48 \\
\hline Electricity and oil & 17.27 & 23.65 & 23.60 & 23.98 \\
\hline Electricity and wood & 11.74 & 9.96 & 9.99 & 10.01 \\
\hline Electricity, oil and wood & 16.08 & 24.06 & 24.16 & 24.38 \\
\hline Demand for power $(\mathrm{kW})$ & 8.22 & 9.12 & 9.19 & 9.59 \\
\hline Income in 1990 or $1993 / 95, Y\left(10^{-5}\right)$ & 3.01 & 2.91 & 2.95 & 2.90 \\
\hline Income when the heating system was purchased, $\mathrm{Y}^{*}\left(10^{-5}\right)$ & 2.62 & 2.70 & 2.75 & 2.70 \\
\hline \multicolumn{5}{|c|}{ Energy price (Nkr/kWh) in 1990 or $1993 / 95$ for heating system based on: } \\
\hline Electricity & 0.36 & 0.42 & 0.40 & 0.42 \\
\hline Electricity and oil & 0.32 & 0.39 & 0.38 & 0.38 \\
\hline Electricity and wood & 0.32 & 0.37 & 0.35 & 0.36 \\
\hline Electricity, oil and wood & 0.31 & 0.37 & 0.35 & 0.36 \\
\hline Chosen technology & 0.32 & 0.38 & 0.36 & 0.37 \\
\hline \multicolumn{5}{|c|}{ Energy price when purchasing the heating system based on $(\mathrm{Nkr} / \mathrm{kWh})$ : } \\
\hline Electricity & 0.31 & 0.36 & 0.36 & 0.36 \\
\hline Electricity and oil & 0.39 & 0.36 & 0.36 & 0.36 \\
\hline Electricity and wood & 0.50 & 0.39 & 0.40 & 0.39 \\
\hline Electricity, oil and wood & 0.48 & 0.38 & 0.38 & 0.38 \\
\hline Ownership $^{5}$ & 0.14 & 0.17 & 0.16 & 0.14 \\
\hline Type of house $^{6}$ & 0.70 & 0.70 & 0.68 & 0.70 \\
\hline Size of household (occupants) & 3.22 & 3.54 & 3.48 & 3.51 \\
\hline Age of the dwelling $\left(10^{-1}\right.$ years $)$ & 0.10 & 1.23 & 1.26 & 1.38 \\
\hline Degree days $\left(10^{-3}\right)$ & 3.20 & 4.12 & 4.14 & 4.13 \\
\hline Observed area $\left(\mathrm{m}^{2}\right)$ & 119.7 & 131.8 & 133.66 & 138.41 \\
\hline Number of children $<16$ years old & 0.98 & 1.17 & 1.17 & 1.23 \\
\hline Number of washing/drying equipment & & 2.22 & 2.22 & 2.36 \\
\hline Number of cooling equipment & & 1.94 & 1.98 & 1.97 \\
\hline Age of oldest occupant & & 42.46 & 43.60 & 43.35 \\
\hline
\end{tabular}

${ }^{1}$ Energy prices, income and the capital cost for 1990 are in constant 1989 prices. US\$ $1=$ Nkr 7.5 (July 1998).

${ }^{2}$ Energy prices, income and the capital cost for the years 1993, 1994 and 1995 are in constant 1993 prices.

${ }^{3}$ Total residential energy consumption is included for the years 1993, 1994 and 1995, while only energy consumption for space heating is included in 1990.

${ }^{4}$ The data sources for purchasing costs and installation costs for 1990 and 1993-95 are different.

${ }^{5}$ Dummy which is 1 if the household lives in housing co-operatives or owner-tenant accommodation, else zero.

${ }^{6}$ Dummy which is 1 if detached house, else zero. 
Table A2. Mean values for pooled data (1993-1995) ${ }^{1}$

\begin{tabular}{|c|c|c|c|}
\hline & $\begin{array}{c}\text { All } \\
\text { household } \\
1503 \text { obs. }\end{array}$ & $\begin{array}{c}\text { Income }< \\
\text { average } \\
787 \text { obs. }\end{array}$ & $\begin{array}{c}\text { Income }> \\
\text { average } \\
716 \text { obs. }\end{array}$ \\
\hline \multicolumn{4}{|l|}{ Share with heating system based on: } \\
\hline Electricity & 0.18 & 0.23 & 0.13 \\
\hline Electricity and oil & 0.02 & 0.02 & 0.02 \\
\hline Electricity and wood & 0.62 & 0.59 & 0.65 \\
\hline Electricity, oil and wood & 0.17 & 0.15 & 0.20 \\
\hline Energy consumption, $\left(10^{-3} \mathrm{kWh}\right)$ & 26.65 & 23.94 & 29.63 \\
\hline \multicolumn{4}{|l|}{ Annual capital cost $\left(10^{-2}\right)$ for heating system based on: } \\
\hline Electricity & 9.48 & 9.52 & 9.43 \\
\hline Electricity and oil & 23.73 & 23.39 & 24.10 \\
\hline Electricity and wood & 9.98 & 10.01 & 9.95 \\
\hline Electricity, oil and wood & 24.19 & 24.00 & 24.41 \\
\hline Demand for power $(\mathrm{kW})$ & 9.29 & 8.07 & 10.64 \\
\hline Net income in 1993,1994 or $1995, \mathrm{Y}\left(10^{-5}\right)$ & 2.92 & 2.05 & 3.87 \\
\hline Income when the heating system was purchased, $Y^{*}\left(10^{-5}\right)$ & 2.72 & 1.91 & 3.60 \\
\hline \multicolumn{4}{|c|}{ Energy price $(\mathrm{Nkr} / \mathrm{kWh})$ in 1993,1994 or 1995 for heating system based on: } \\
\hline Electricity & 0.41 & 0.42 & 0.41 \\
\hline Electricity and oil & 0.38 & 0.39 & 0.38 \\
\hline Electricity and wood & 0.36 & 0.36 & 0.36 \\
\hline Electricity, oil and wood & 0.36 & 0.36 & 0.36 \\
\hline Chosen technology & 0.37 & 0.37 & 0.37 \\
\hline \multicolumn{4}{|c|}{ Energy price (Nkr/kWh) when purchasing the heating system based on: } \\
\hline Electricity & 0.36 & 0.36 & 0.36 \\
\hline Electricity and oil & 0.36 & 0.36 & 0.36 \\
\hline Electricity and wood & 0.39 & 0.39 & 0.39 \\
\hline Electricity, oil and wood & 0.38 & 0.38 & 0.38 \\
\hline Ownership ${ }^{2}$ & 0.15 & 0.18 & 0.12 \\
\hline Type of house ${ }^{3}$ & 0.69 & 0.65 & 0.74 \\
\hline Size of household (occupants) & 3.51 & 3.23 & 3.82 \\
\hline Age of the dwelling $\left(10^{-1}\right.$ years $)$ & 1.28 & 1.25 & 1.32 \\
\hline Degree days $\left(10^{-3}\right)$ & 4.13 & 4.15 & 4.11 \\
\hline Observed area $\left(\mathrm{m}^{2}\right)$ & 134.48 & 118.51 & 152.03 \\
\hline Number of children $<16$ years old & 1.19 & 1.21 & 1.16 \\
\hline Number of washing/drying equipment & 2.26 & 2.07 & 2.48 \\
\hline Number of cooling equipment & 1.97 & 1.88 & 2.06 \\
\hline Age of oldest occupant & 43.14 & 42.22 & 44.16 \\
\hline
\end{tabular}

${ }^{1}$ Energy prices, costs and income are in constant 1993 prices

${ }^{2}$ Dummy which is 1 if the household lives in housing co-operatives or owner-tenant accommodation, else zero.

${ }^{3}$ Dummy which is 1 if detached house, else zero. 


\section{Appendix B}

\section{Estimation results based on the 1990 Energy Survey}

Table B1. The choice of heating system and energy consumption for space heating in dwellings from 1971-1990. The reference choice is electricity (parameter $=0$ ). 550 dwellings

\begin{tabular}{|c|c|c|}
\hline Variable & Estimate & t-ratio \\
\hline Income, $Y$ and heating system costs. $(\beta)$ & 0.16 & 2.78 \\
\hline \multicolumn{3}{|l|}{ Dwelling ownership } \\
\hline \multicolumn{3}{|l|}{ Choice of heating system: } \\
\hline Electricity + oil & -1.82 & -2.33 \\
\hline Electricity + wood & -1.08 & -3.56 \\
\hline Electricity + oil + wood & -3.52 & -3.66 \\
\hline \multicolumn{3}{|l|}{ Type of house } \\
\hline \multicolumn{3}{|l|}{ Choice of heating system: } \\
\hline Electricity + oil & 1.36 & 2.01 \\
\hline Electricity + wood & 2.59 & 6.42 \\
\hline Electricity + oil + wood & 2.19 & 4.85 \\
\hline \multicolumn{3}{|l|}{ Size of household } \\
\hline \multicolumn{3}{|l|}{ Choice of heating system: } \\
\hline Electricity + oil & -0.02 & -0.08 \\
\hline Electricity + wood & 0.38 & 3.78 \\
\hline Electricity + oil + wood & 0.36 & 2.94 \\
\hline \multicolumn{3}{|l|}{ Income, $Y^{*}$} \\
\hline \multicolumn{3}{|l|}{ Choice of heating system: } \\
\hline Electricity + oil & -0.64 & -2.52 \\
\hline Electricity + wood & -0.13 & -1.46 \\
\hline Electricity + oil + wood & -0.44 & -3.45 \\
\hline Constant & -5.68 & -2.23 \\
\hline Predicted size of the dwelling ${ }^{1}$ & 0.07 & 6.35 \\
\hline Degree days & 2.79 & 7.91 \\
\hline Energy price of technology $j$ & -9.39 & -1.99 \\
\hline Temperature regulation & 1.32 & 2.87 \\
\hline Number of floors in the dwelling & 1.01 & 2.99 \\
\hline Energy saving strategies & 0.36 & 0.82 \\
\hline \multicolumn{3}{|l|}{ Selection term } \\
\hline \multicolumn{3}{|l|}{ Choice of heating system: } \\
\hline Electricity & 0.59 & 1.37 \\
\hline Electricity + oil & 1.93 & 3.89 \\
\hline Electricity + wood & 3.62 & 4.04 \\
\hline Electricity + oil + wood & 3.93 & 5.48 \\
\hline \multicolumn{3}{|l|}{ Residual variance } \\
\hline \multicolumn{3}{|l|}{ Choice of heating system: } \\
\hline Electricity & 3.16 & 12.98 \\
\hline Electricity + oil & 5.04 & 5.52 \\
\hline Electricity + wood & 6.13 & 25.16 \\
\hline Electricity + oil + wood & 7.19 & 13.82 \\
\hline
\end{tabular}

${ }^{1}$ Income at the point when the heating technology was purchased, the type of house and the size of household are used as instruments when estimating the dwelling size. 


\section{Appendix C}

Results from estimating the dwelling size (by OLS)

\begin{tabular}{l|rr|rr|rr|rr}
\hline \multirow{2}{*}{ Variables } & \multicolumn{2}{|c|}{$\mathbf{1 9 9 3 - 9 5}$} & \multicolumn{2}{|c|}{$\mathbf{1 9 9 3}$} & \multicolumn{2}{c}{$\mathbf{1 9 9 4}$} & \multicolumn{2}{c}{1995} \\
\hline Constant & Estimate & t-ratio & Estimate & t-ratio & Estimate & t-ratio & Estimate & t-ratio \\
Income* & 51.51 & 14.13 & 39.81 & 6.21 & 47.32 & 7.72 & 64.02 & 10.0 \\
Type of house & 12.18 & 13.94 & 17.26 & 9.82 & 13.59 & 9.06 & 8.00 & 5.99 \\
Household size & 36.01 & 14.19 & 31.26 & 6.95 & 35.71 & 8.83 & 41.82 & 9.04 \\
\hline * Income when the house was built in Nkr·10 & 6.89 & 7.57 & 6.33 & 4.01 & 6.96 & 4.65 & 6.51 & 3.94 \\
\hline
\end{tabular}




\section{References}

Baker, P., R. Blundell and J. Micklewright (1989): Modelling household energy expenditures using micro-data. The Economic Journal 99, 720-738.

Bernard, J.T., D. Bolduc and D. Bélanger (1996): Quebec residential electricity demand: a microeconometric approach, Canadian Journal of Economics XXIX, 1, 92-113.

Branch, E.R. (1993): Short run income elasticity of demand for residential using consumer expenditure survey data, The Energy Journal 14, 4, 111-121.

Dennerlein, R.K.H. (1987): Residential Demand for Electrical Appliances and Electricity in Federal Republic of Germany, The Energy Journal 8, 1, 60-86.

Dubin, J.A. and D.L. McFadden (1984): An Econometric Analysis of Residential Electric Appliance Holdings and Consumption, Econometrica 52, 2, 345-362.

Garbacz, C. (1983): A model of residential demand for electricity using a national household sample, Energy Economics 5, 2, 124-128.

Halvorsen, B. and B.M. Larsen (1998): The Dynamics of Residential Electricity Consumption in Household Production: A Microeconometric Analysis, Conference Proceedings 1, 21st Annual International Conference of the IAEE. Québec City, Canada, 351-360.

Hausman, J.A. (1979): Individual discount rates and the purchase and utilization of energy-using durables, The Bell Journal of Economics 10, 1, 33-54.

Henley, A. and J. Peirson (1998): Residential energy demand and the interaction of price and temperature: British experimental evidence, Energy Economics 20, 2, 157-171.

IFE (1995): Heating equipment in the households. Institute for Energy Technology, 95/004, Norway. (In Norwegian).

McFadden, D. (1973): “Conditional Logit Analysis of Qualitative Choice Behavior”, in ed. P. Zarembka: Frontiers in Econometrics, New York, Academic Press.

Morss, M.F. and J.L. Small (1989): Deriving Electricity Demand Elasticities from a Simulation Model, The Energy Journal 10, 3, 51-76.

Nesbakken, R. (1998): Residential Energy Consumption for Space Heating in Norwegian Households. A Discrete-Continuous Choice Approach, Discussion Papers No. 231, Statistics Norway.

Parti, M. and C. Parti (1980): The total and appliance-specific conditional demand for electricity in the household sector, The Bell Journal of Economics 11, 1, 309-321.

Poyer, D.A., L. Henderson and A.P.S. Teotia (1997): Residential energy consumption across different population groups: comparative analysis for Latino and non-Latino households in USA, Energy Economics 19, 445-463. 
Statistics Norway (1998). Energibruk i husholdningene, 1993-1995 (Household Energy Consumption, 1993-1995), Weekly Bulletin of Statistics No. 24.

Vaage, K. (1998): Samanlikning av eldre og nyare metodar for analyser av elektrisitetsetterspurnad: Teoretiske aspekt og empiriske resultat (Comparing Older and Newer Methods of Analysing the Electricity Demand: Theoretical Aspects and Empirical Results), Norsk Økonomisk Tidsskrift 112, 1, $35-60$.

Yamasaki, E. and N. Tominaga (1997): Evolution of an aging society and effect on residential energy demand, Energy Policy 25, 11, 903-912.

Aasness, J. and B. Holtsmark (1993): Consumer Demand in a General Equilibrium Model for environmental Analysis, Discussion Papers No. 105, Statistics Norway. 